\title{
LUDUS SPHAERAE PER ANNULUM FERREUM: TRADICIÓN ALEGÓRICO- EMBLEMÁTICA DEL BEUGELEN
}

\author{
LUDUS SPHAERAE PER ANNULUM FERREUM: THE ALLEGORICAL- \\ SYMBOLIC TRADITION OF BEUGELEN
}

José Javier Azanza López

Universidad de Navarra

ABSTRACT: Beugelen was a game, described early on by Erasmus, which gained wide popularity in the Netherlands, played both in palaces and villages, as evidenced by numerous engravings of the 16th and 17th Centuries. Therefore, it is not surprising to find its allegorical-symbolic exploitation, associated with concepts such as mental laziness (Heinrich Aldegrever), the fatal consequences of the game (Johannes David) and the effects of human and divine love (Peter Rollos, Typus mundi, Ludovicus van Leuven and Willem den Elger). In the light of previous emblematic repertories, I delve into the meaning of a number of paintings, paying special attencion to works of Lucas Gassel (David and Bathsheba), Gerrit Lundens (People Playing Croquet in the Courtyard of an Inn) and Jan Steen (Garden Party).

KEYWORDS: Beugelen, Netherlands, 16th and 17th Centuries, Emblematic Images, Painting.

RESUMEN: El beugelen es un juego ya descrito por Erasmo que adquirió gran popularidad en los Países Bajos, practicándose tanto en aldeas como en palacios, como testimonian numerosos grabados de los siglos XVI-XVII. No resulta extraño por tanto su aprovechamiento simbólico-emblemático, asociado a conceptos como la pereza mental (Heinrich Aldegrever), las fatales consecuencias del juego (Johannes David) y los efectos del amor divino y humano (Peter Rollos, Typus mundi, Ludovicus van Leuven y Willem den Elger). A la luz de los anteriores repertorios emblemáticos tratamos de profundizar en el significado de algunas pinturas, prestando especial atención a obras de Lucas Gassel (David y Betsabé), Gerrit Lundens (Personas jugando a los bolos en el patio de una posada) y Jan Steen (Fiesta en el jardín).

PALABRAS CLAVES: beugelen, Países Bajos, siglos XVI y XVII, emblemática, pintura. 
Si en anteriores trabajos hemos dedicado nuestra atención al valor simbólico de modalidades deportivas como el tenis (Azanza López, 2011-12: 11-39) y el pallone col bracciale (Azanza López, 2015: 103-117), con especial aplicación en Francia e Italia respectivamente, en esta ocasión nos detendremos en el beugelen, completando así nuestra particular trilogía deportivo-emblemática.

\section{EL BEUGELEN Y SU POPULA- RIDAD EN LOS PAÍSES BAJOS}

El beugelen es un juego de rica tradición histórica cuyos orígenes se remontan al siglo XIV; llegó a captar el interés de Erasmo, quien en sus Coloquios (1518) lo denomina Ludus sphaerae per annulum ferreum (Morgan, 1995: 168-173), y del humanista alemán Hermann Schotten, quien en sus Confabulationes (1525) se refiere al mismo como De ludo globorum qui torquentur per annulum (Macardle, 2007: 149-151 y 510-511), al mismo tiempo que era representado en un retablo escultórico de la iglesia alemana de Kempen (1513).

Su objetivo consiste en hacer pasar las bolas a través de una anilla empujándolas con una pala de extremo acanalado, en un terreno de juego rectangular de $5 \times 10 \mathrm{~m}$. en el que la anilla queda fijada a $2,5 \mathrm{~m}$. del borde trasero, de manera que debe embocarse por el lado delantero. Su práctica se extendió por toda Europa, en países como Francia (donde se denominó passe) y Gran Bretaña (troco); pero fue en los Países Bajos donde alcanzó mayor tradición, al punto de que hoy en día todavía sobrevive en las provincias de Brabante y Limburgo.

Tal popularidad obedece a diversos factores, comenzando por el hecho de que podía practicarse a cualquier edad, como testimo- nian numerosos grabados de los siglos XVI y XVII. En el caso infantil, lo comprobamos en la serie Septem Planetae (1581) de Adriaen Collaert, cuyo grabado dedicado a la LunaInfancia incluye un grupo de niños jugando al beugelen en su modalidad de herramienta corta. ${ }^{1}$ Contemporáneo es el Speculum Vitae Humanae per decem aetatis gradus distinctum, que recoge el beugelen entre las actividades propias de la segunda década del hombre ${ }^{2}$ [fig. 1]. Vinculado asimismo a la edad infantil se encuentra en Ludi pueriles, uno de los grabados de Orbis Sensualium Pictus (1657), enciclopedia ilustrada para niños escrita por el educador checo Johan Amos Comenius.

Pero el beugelen es también juego de adultos, practicándose por igual en aldeas y palacios. Forma parte de las kermeses o bambochadas populares, combinación de

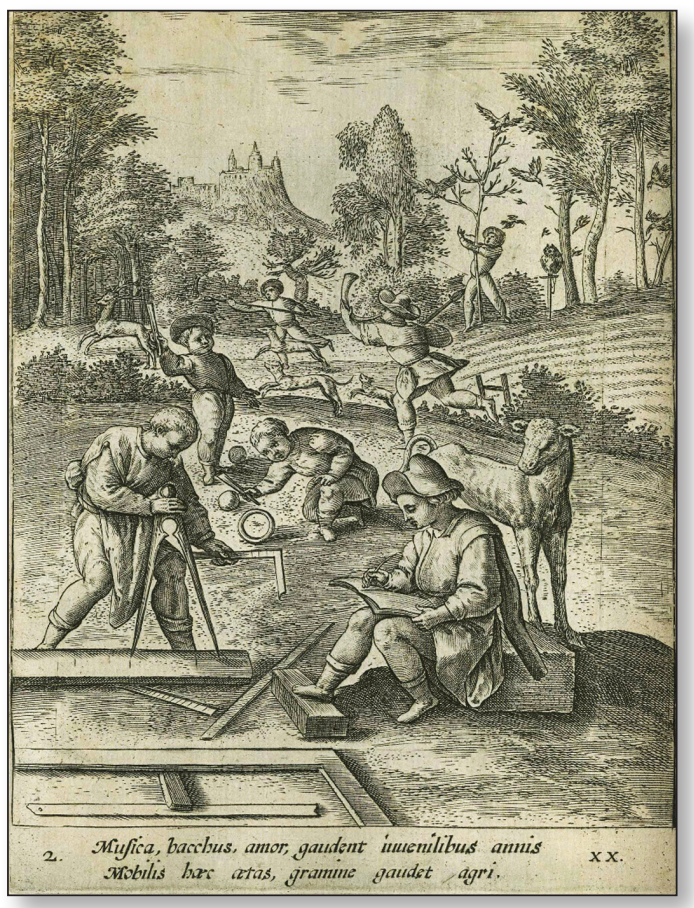

Fig. 1. Speculum Vitae Humanae per decem aetatis gradus distinctum. Segunda década del hombre.

1. The New Hollstein Dutch $\theta$ Flemish Etchings, 2005: 19-23.

2. Hollstein's Dutch $\theta$ Flemish Etchings, 1995: 227. 


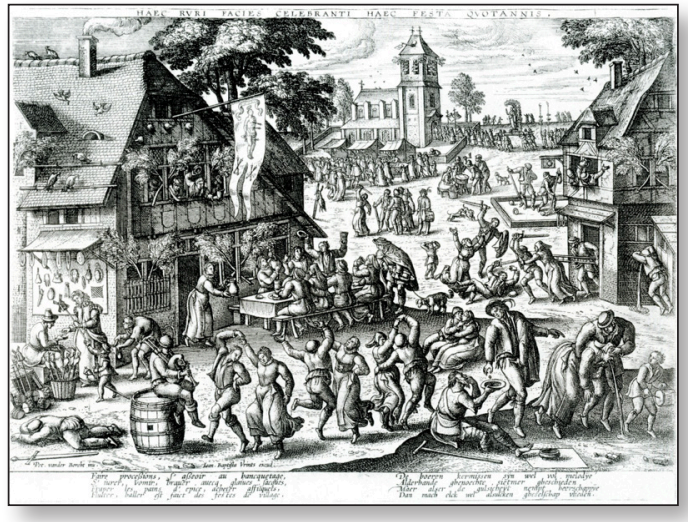

Fig. 2. Peeter van der Borcht. Fiesta de san Sebastián.

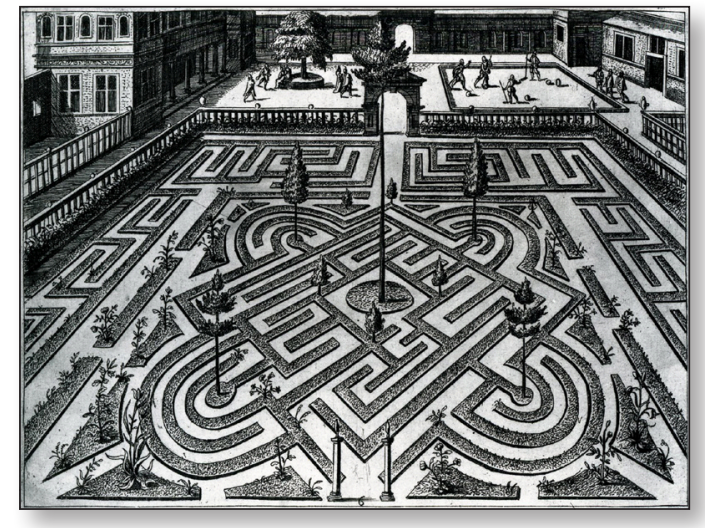

Fig. 3. Jan Vredeman de Vries. Hortorum Viridariorumque elegantes $\theta$ multiplicis formae.

cidad para las construcciones escenográficas en perspectiva (Kemp, 2000: 121-131; Heuer: 2009), compuso en la década de 1580 una serie de grabados asociados a un texto sobre el diseño del jardín renacentista que muestran vistas de jardines con parterres, en uno de los cuales cuatro hombres juegan al beugelen en el patio del fondo ante la atenta mirada de tres espectadores (Vredeman de Vries, 1583) [fig. 3].

Semejante reiteración del beugelen en el grabado hacía presagiar su presencia en la literatura emblemática de la época, asociado a la transmisión de una enseñanza moral.

\section{PRESENCIA DEL BEUGELEN EN LOS LIBROS DE EMBLEMAS}

\section{ENTRE LA PEREZA Y LOS EFECTOS PERNICIOSOS DEL JUEGO}

Una de las referencias más tempranas proviene del alemán Heinrich Aldegrever (1502-h. 1555), especializado en grabados

3. The New Hollstein Dutch $\theta$ Flemish Etchings, 2004: 174-175 y 183-184.

4. Ídem, 2006: 102-103. Se ha suscitado entre los especialistas del arte flamenco un interesante debate acerca del trasfondo que quieren transmitir van der Borcht y Brueghel con sus imágenes, para el que nos remitimos a Sullivan, 1994: 41-42; y Orenstein, 2001: 196-197. 


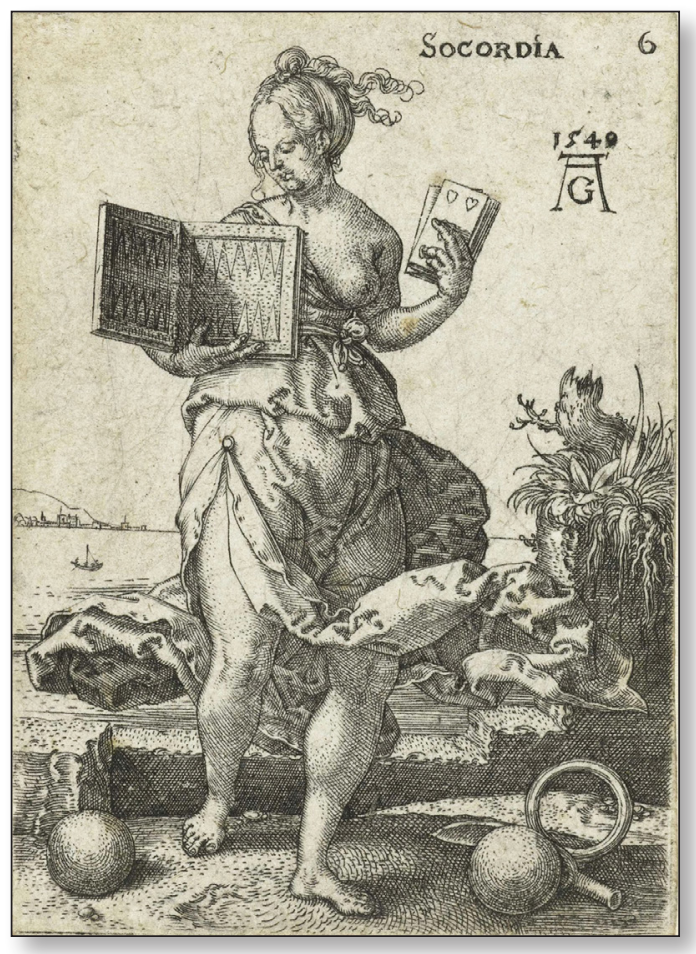

Fig. 4. Heinrich Aldegrever. Socordia.

de pequeño formato en los que resulta perceptible la influencia de Durero. En 1549 compuso una serie de catorce grabados de personificaciones de virtudes y vicios representados por figuras femeninas con sus respectivos atributos. ${ }^{5} \mathrm{El} \mathrm{n}{ }^{\circ} 6$ se denomina Socordia [fig. 4], término latino que expresa una especie de indiferencia en lo tocante a los conocimientos útiles, un adormecimiento voluntario que san Agustín señala como impedimento de nuestra diligencia para buscar la verdad (De la Peza, 1961: 347). Semejante actitud se representa mediante una mujer joven en medio de un paisaje costero, mostrando un tablero de tric-trac y una baraja de naipes, en tanto que a sus pies son visibles los objetos del beugelen. No estará de más recordar que, en la Edad Moderna, la imaginería asociada a los juegos de mesa y azar simboliza la vanidad de los bienes terrenales y los vicios de quienes se apartan de las cosas más graves para atender a fiestas y otras vanidades, malgastando su vida (Bergström, 1956: 154). Y en este sentido debemos interpretar la composición de Aldegrever, en tanto en cuanto el juego se convierte en símbolo de pereza mental y de alejamiento de las cosas importantes.

Precisamente a los efectos perniciosos del juego alude Veridicus Christianus (Amberes, 1601), del jesuita belga Johannes David, catecismo en imágenes compuesto por cien grabados con leyendas en latín, holandés y francés, e inspirado en gran medida en las Evangelicae historiae imagines (Amberes, 1593) de Jerónimo Nadal, en el sentido en que las diferentes escenas que se yuxtaponen en cada plancha son identificadas por pequeñas letras del alfabeto que remiten al texto explicativo (Insolera y Salviucci, 1996: 141-145; Daly, 1999: 252). Mas los grabados de Théodore Galle abandonan la realidad evangélica para ilustrar aspectos más teóricos y fortalecer el alma del lector a través de un rico caudal de explicaciones, con el claro objetivo de reforzar sus convicciones interiores (Porteman, 2000: 187).

El grabado $\mathrm{n}^{\circ} 5$ [fig. 5] lleva por mote "Tria ad animae perniciem indvcentia" [Tres cosas conducen a la ruina del alma], sentido que se completa con el dístico inferior: "¿Qué es lo que nos arrastra, más temprano que tarde, al abismo infernal? Es la compañía, el consejo, la vida, de aquellos que se comportan mal». David concreta en tres vías la recepción de perniciosas influencias: a través de los malos consejos, de los malos ejemplos y de las malas compañías. Para estas últimas acude al versículo "Comparte tu suerte con nosotros, haremos bolsa común» (Prov 1,8-19), que previene sobre las peligrosas compañías que apartan de la senda de la verdad, ejemplificadas (D) mediante un grupo de jóvenes que incitan a diversos vicios como la bebida, las peleas y

5. German Engravings, Etchings and woodcuts, 1954: 57; The Illustrated Bartsch, 1980: 191. 


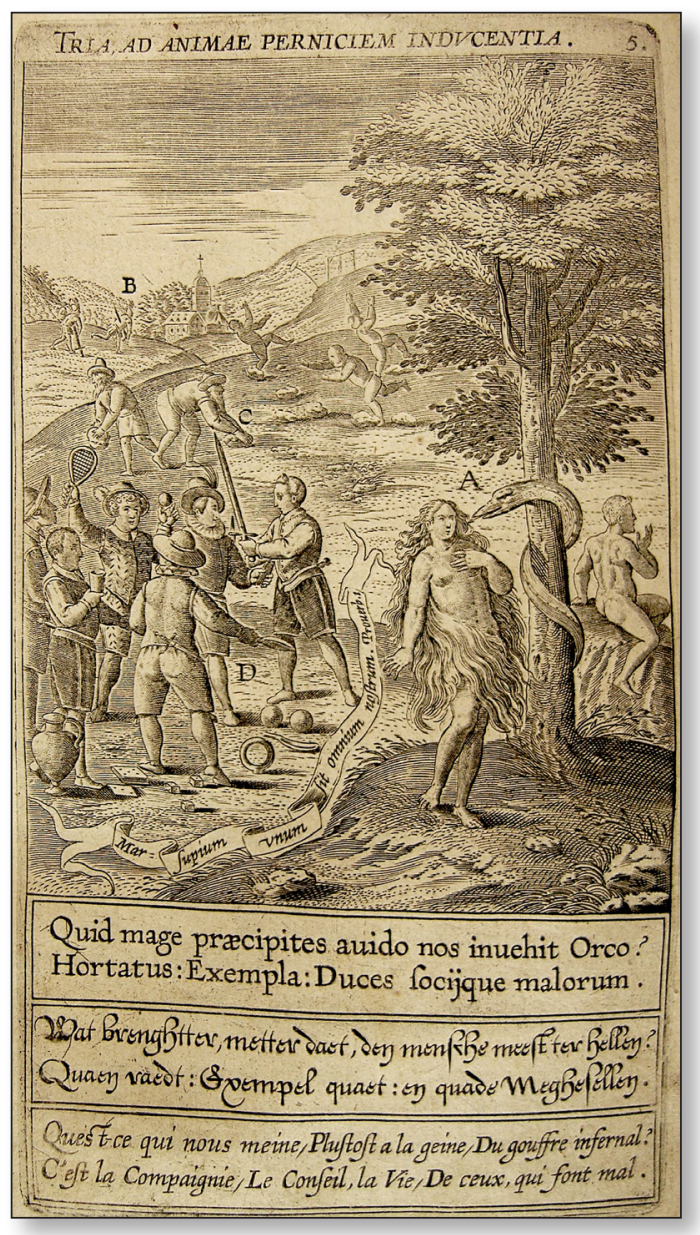

Fig. 5. Johannes David, Veridicus Christianus. Grabado $\mathrm{n}^{\circ} 5$.

el juego, con presencia de naipes y dados y la práctica del tenis y del beugelen, cuyos instrumentos son perfectamente visibles junto al hombre de espaldas que ciñe un puñal a la cintura. El mensaje es evidente: debemos huir de las malas compañías que buscan tan solo los placeres terrenales, en los que no encontraremos sino ruina y perdición, idea en la que insiste David aportando otras reflexiones acerca de las compañías inadecuadas extraídas de las Cartas de san Bernardo y de las Sátiras de Juvenal.

\section{LOS EFECTOS DEL AMOR HUMANO Y DEL AMOR DIVINO}

Cambiemos de registro para aproximarnos a la presencia del beugelen en los libros del alemán Peter Rollos, compuestos por emblemas de naturaleza satírico-amorosa concebidos en el espíritu de los fabliaux medievales franceses, a través de los cuales moraliza a la juventud acerca de los vicios a los que conduce la libertad mal entendida. El autor explora las posibilidades del tema en Philotheca Corneliana (h. 1619), Vita Corneliana emblematibus in aes artificiose incisa (1624-25) y Vita Corneliana, sive Cytherea studiosorum (1639), en los cuales el cortejo amoroso es representado mediante distintos juegos de los que extrae una enseñanza. Su éxito fue tal que en la segunda mitad del siglo XVII vieron la luz nuevas ediciones e incluso se tradujeron al francés bajo el título Le centre de l'amour decouvert soubs divers emblesmes galans et facetieux (1680). En esta última, las materias son tratadas de una manera a la vez tan delicada y equívoca que pueden agradar a los oídos castos y al mismo tiempo hacer la delicia de quienes gustan de los mensajes con doble sentido.

La práctica del beugelen aparece en la mayoría de las publicaciones citadas, comenzando por Philotheca Corneliana, en una escena en la que los personajes visten elegantes ropajes que le confieren carácter cortesano, a lo que contribuye igualmente la heráldica del primer plano. Posteriormente lo encontramos en Vita Corneliana, sive Cytherea studiosorum, en un grabado que volverá a repetirse en Le centre de l'amour, donde con el título "La Passe» [fig. 6] se convierte en el tercero de los 92 emblemas que componen la obra. La escena se ambienta en el jardín del amor, con una pareja disfrutando de un picnic en primer plano y otra que camina hacia el fondo, cerca de unos pavos reales cuya presencia incide en su significado amoroso. Los versos franceses, dentro de ese calculado doble lenguaje, 


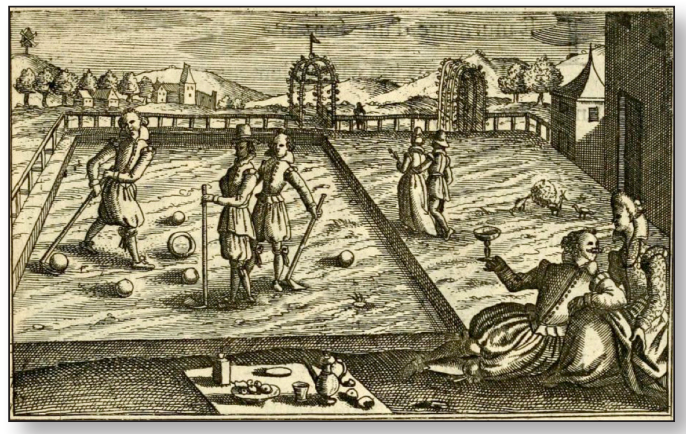

Fig. 6. Le centre de l'amour. Emblema $\mathrm{n}^{\circ} 3$.

hacen referencia a la necesidad de actuar con determinación tanto en el juego como en el amor, pues en ambos casos la indecisión no lleva sino a consumir la vida de una manera inútil. ${ }^{6}$

Elevemos ahora el tono moral del mensaje. Obra de gran interés no solo por su contenido, sino por su posterior influencia, es Typus mundi (1627), compuesta por un grupo de colegiales bajo la dirección de Jean Matthiae, profesor de retórica en el Colegio de la Compañía de Jesús de Amberes (Moseley, 1989: 183-201; Daly, 1999: 253). Sus 33 emblemas alegóricos -en el carácter inusual de alguno de ellos hay quien ha querido ver un significado alquímico ${ }^{7}$ muestran la oposición entre el amor divino y el humano, que tratan de salvar o de condenar al mundo, tal y como explicitan los textos en latín, francés y holandés que acompañan a cada imagen.

El emblema 26 [fig. 7] lleva por mote "Hâc vincitur, illâc perditur» [Por un lado triunfa, por el otro pierde]. Protagoniza la pictura una partida de beugelen entre el amor divino y el humano, el primero de los cuales ha golpeado la bola del mundo hacia la

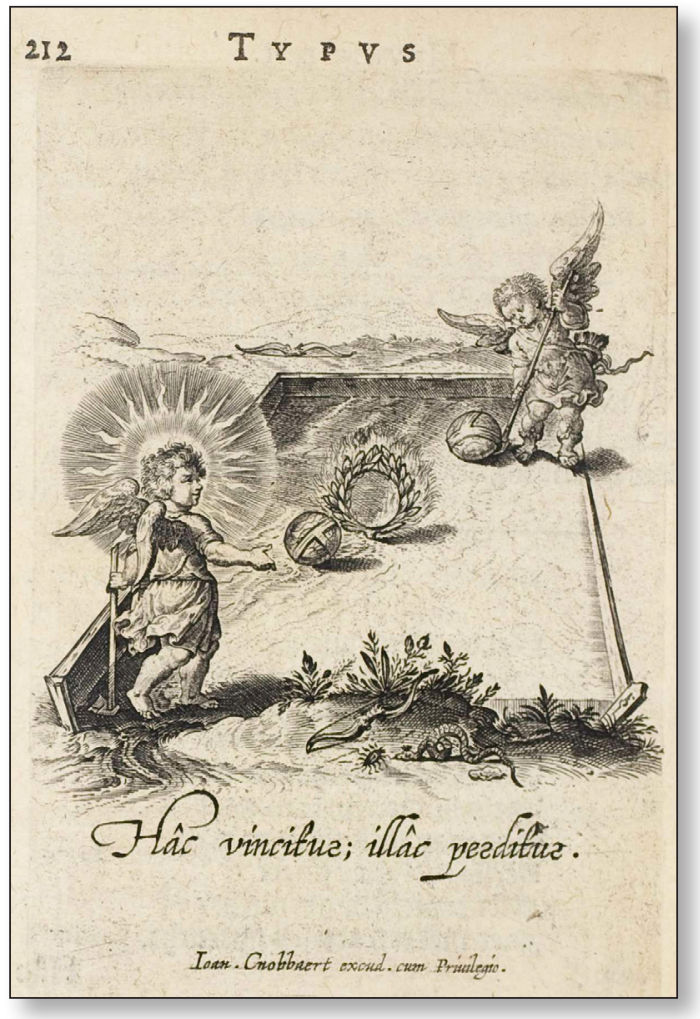

Fig. 7. Typus mundi. Emblema no 26.

anilla, que en este frente se rodea de una corona de laurel, en tanto que el segundo se dispone a hacer lo propio con la suya para hacerla avanzar hacia las llamas del fuego. La imagen nos enfrenta a la omnipotencia del amor, que mueve el mundo como si de un juego se tratara; pero existen dos clases de amor, y es aquí donde los textos acuden en auxilio de la pictura. El extenso comentario latino, que se sirve de un conjunto de referencias a escenarios y personajes del mundo clásico en su admonición para despreciar las riquezas caducas y ambicionar los tesoros eternos, concluye que solo

6. La traducción aproximada de los versos franceses dice así: «A qué buen equilibrio, ¿por qué arder de envidia / y consumir la vida de una manera tan tonta? / ¡Qué lentos y vanos / son el estudio de los ojos y los discursos de las manos! / El retraso me deprime. / Yo paso mis bolas a tiro hecho. / Y rápido se puede entender / que no soy uno de esos patosos / y que consigo ser entusiasta / cuando es necesario empujarla en la passe».

7. Es el caso de Eugène Canseliet en su Prefacio a la segunda edición francesa (1958) de Las Moradas Filosofales de Fulcanelli, si bien no alude a este emblema en concreto. El propio Fulcanelli cita Typus Mundi en El Misterio de las Catedrales, 2009: 169-170. No llegamos a verlo recogido en Emblems and Alchemy, 1998. 
la vida virtuosa merece el laurel del triunfo. ${ }^{8} \mathrm{Y}$ en ello insiste el epigrama holandés al significar que Cupido pierde al lanzar la bola desde atrás, en tanto que el amor divino juega desde adelante y logra la victoria; debemos entender el comentario a la luz de las normas del juego, según las cuales hay que pasar la bola por el lado delantero del campo, siendo penalizado quien emboca por detrás. En definitiva, el amor divino nos guía por la senda de la virtud para lograr la victoria de la vida eterna, en tanto que el amor humano nos conduce al fuego del infierno.

Hasta aquí el mensaje parece claro; mas el epigrama francés se torna complejo a la hora de descifrar su significado. Alude al forzoso matrimonio de Dafne con Vulcano, enlace entre la gloria y el desprecio que pone en riesgo el premio de la victoria. Debemos dirigir nuestra mirada a la anilla del juego, en la que confluyen el laurel como símbolo de la ninfa, y el fuego con el que forja el hierro el desairado dios en su fragua. Tanto el laurel como el fuego y el hierro tienen un significado alquímico. ${ }^{9}$ ¿Proporcionan las claves para una interpretación hermética que va más allá de la aparente victoria del amor divino? No somos capaces de dar una respuesta válida, si bien no podemos ignorar que este es el único caso en el que la anilla del beugelen se muestra laureada e ígnea.
Contemporáneo del anterior es Amoris divini et humani antipathia (1629), escrito por el flamenco Ludovicus van Leuven (h. 16001661). De historia editorial compleja, ${ }^{10}$ está compuesto por 83 emblemas, cuya organización interna sigue de cerca la estructura de Amoris Divini Emblemata (1615) de Otto Vaenius, de manera que el epigrama latino que acompaña a la pictura se complementa con citas en francés, español ${ }^{11}$ y neerlandés, dotando así a la obra de un marcado poliglotismo. En su idea general, las obras del demonio se contraponen a las de Dios, y los efectos del amor humano a los del divino; de ahí su estructura en dos libros, el primero dedicado al amor humano, y el segundo, a partir del emblema 43, al divino, con una clara moralidad acerca de los «malos y santos efectos» de uno y otro (Praz, 1989: 161-162).

Nos fijamos en el emblema 48, que con el mote "Lusus Amoris» [Juego del Amor], muestra al amor divino jugando al beugelen con una figura femenina, personificación del alma humana [fig. 8]; al igual que ocurriera en Typus mundi, una de las bolas representa al mundo. ${ }^{12}$ Acompañan a la imagen dos citas en latín y francés, la primera extraída de los Prov 8,31: "Jugaba con el orbe de la tierra, y mi alegría era estar con los hombres», en tanto que la segunda se concreta en un refrán: "En los juegos del amor, aquel que pierde, gana siempre», inspirado en la cita: «Pero lo que entonces consideraba una ganancia, ahora lo considero pérdida por amor

8. Tras citar a reyes y dioses como Creso, Pluto y Furina, así como a los personajes horacianos Ulises y Alcínoo, el texto finaliza con la siguiente reflexión: "La sola virtud ceñirá tus cabellos con el honor del Laurel. / La Virtud engendra delicias, la única Virtud engendra triunfos... / Siendo esta la guía, si juegas vences, si no jugases, yerras: / se vence por esta, por aquella se pierde. ¡Oh, qué haces!».

9. Y también la serpiente coronada, si es así como aparece en primer plano. Atienza, 1995: 395-396 y 481; y Warlick, 2003: 18-20.

10. Está basada en ediciones anónimas de 1626 y 1628, y además incorpora numerosos emblemas de Typus mundi. Adams, Rawles y Saunders, 1999: 120-136.

11. En el caso de Amoris Divini Emblemata, el tercetillo español fue compuesto por Alonso de Ledesma, tal y como refiere el propio Vaenius en el prefacio del libro. López Poza, 2007: 93-109. Parece poco probable que vuelva a ser Ledesma en el caso de Amoris divini et humani antipathia, dado que había fallecido en 1623.

12. Tanto la pictura -con mínimas variantes-como el mote y las citas en latín y francés, hacían acto de presencia en la edición anónima de 1628 Amoris divini et humani antipathia, protagonizando el emblema $\mathrm{n}^{\circ} 32$. Partiendo de ella, van Leuven amplía el comentario e introduce nuevas citas en español y holandés. 


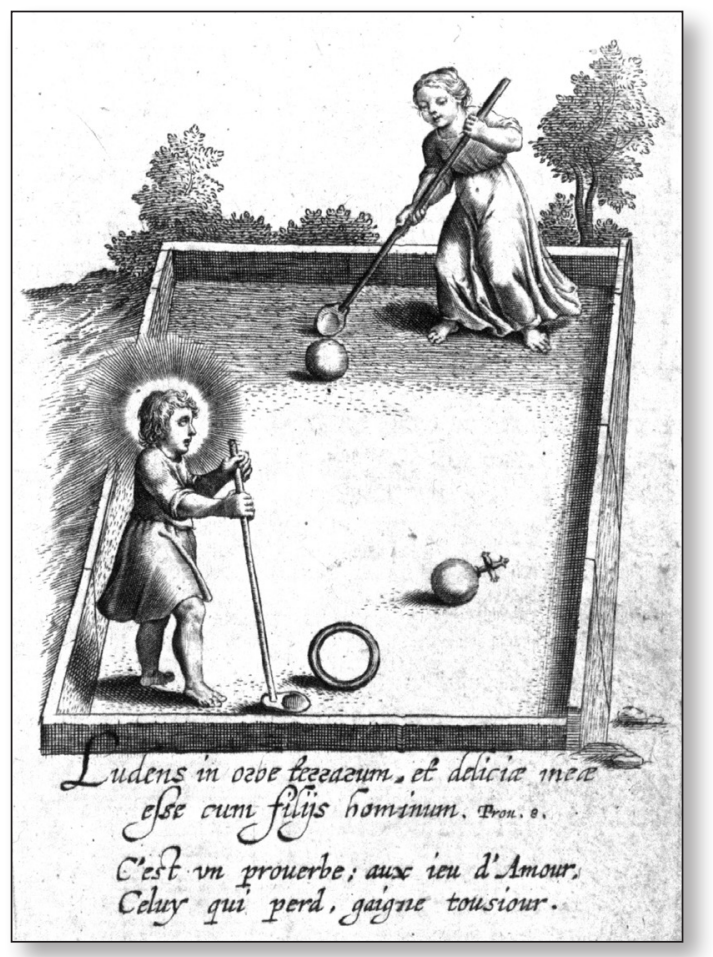

Fig. 8. Ludovicus van Leuven, Amoris divini et humani antipathia. Emblema $\mathrm{n}^{\circ} 48$.

a Cristo» (Flp 3,7), en relación con el valor de conocer y amar al Señor.

Los anteriores conceptos son desarrollados en el comentario al versículo proverbial del dominico francés Hugo de san Caro (h. 1200-1263), para quien el mundo es como un juego, cuyas reglas cambiantes son impuestas por los pueblos que lo dominan; y se pregunta por la enseñanza de todo ello, conectando con el versículo «El Señor... va a hacer que ruedes como pelota hacia un vasto país. Allí morirás» (Is 22,18). ${ }^{13}$ Sin embargo, el libro de emblemas se separa de esta advertencia al significar que es el amor el que golpea la pelota; mas hay dos clases de amor: el del mundo, un amor desorde- nado que dispara para dividir y destruir; y el divino, que lanza la bola siempre en la misma dirección, conforme a las reglas de la Iglesia que se concretan en los decretos papales que sirven para proteger y defender. Las citas finales en francés, español y holandés aluden a las ganancias que suponen las pérdidas por amor a Cristo, entroncando así con la sentencia paulina. En definitiva, el emblema viene a significar que, en el juego de pelota al que se equipara el mundo, es necesario seguir las normas universales de la Iglesia, por medio de las cuales se alcanzará el triunfo de la vida eterna.

En este circuito amoroso por el que transitamos, retornamos a la temática del amor humano de la mano del holandés Willem den Elger (h. 1677-1703), autor de Zinnebeelden der liefde (1703). De la colección de 50 emblemas que lo configuran, el $\mathrm{n}^{\circ}$ 22 va encabezado por la sentencia "Liefde is de beste leermeester» [El amor es el mejor maestro] [fig. 9]. Su pictura reproduce casi literalmente la de Amoris divini et humani antipathia: asistimos a una partida de beugelen entre un joven y una muchacha, con el mundo como una de las bolas del juego; la diferencia estriba en que desaparece la aureola divina del primero, identificándose por tanto con el amor humano. A partir del sexteto a modo de epigrama, ${ }^{14}$ los textos en distintos idiomas de las páginas siguientes constituyen una especie de «camino de perfección amorosa» en el que ejercen de guías reconocidos autores en la materia: el filósofo y poeta romano Boecio (De consolatione Philosophiae, h. 524), quien considera que el amor es el mejor maestro (Boecio, 1997: 235-238); el poeta y dramaturgo italiano Giovanni Battista Guarini (Il pastor fido, 1589), cuyo consejo parece ser actuar con rigor y no con blandura; ${ }^{15}$ el dramatur-

13. Biblia latina, cum postillis Hugonis de Sancto Charo, h. 1500: s.p.

14. «No te preocupes, permite al Amor conquistarte, / Él sabe mucho mejor cómo manejar el mundo, / Él está acostumbrado a lanzar siempre la bola, / aunque esta pequeña pérdida se convertirá en tu ventaja. / Es una ley segura para quien ama / que aunque pierda muchas veces, a menudo gana la batalla» .

15. Guarini, 1976: 43. Pese a inscribirse dentro de la literatura pastoril italiana junto a obras que establecieron las 
LIEFDE IS DE RESTE LEERMEESTER:

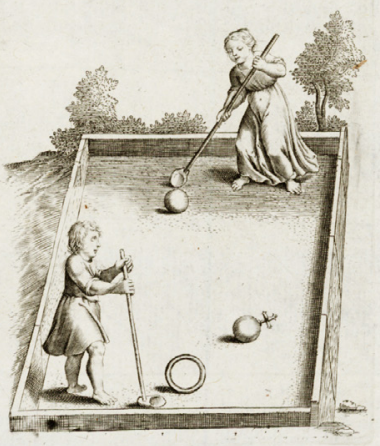

Zy niet bekommert, laat de liefde u overheeren;

Zy weet veel beter met de waereld om te gaan

$\mathbf{Z y}$ is altyd gewent die ronde bol te flaan,

Dog dit gering verlies zal tot uw voordeel keererr.

Het is een vafte wet voor ymand die bemine

Dat als hy' $t$ meeft' verlieft, hy dikmaals' $t$ meefte wists

Fig. 9. Willem den Elger, Zinne-beelden der liefde, emblema $\mathrm{n}^{\circ} 22$.

go francés Philippe Quinault (Astrate, roy de $T y r$, 1664), para quien no siempre el esfuerzo garantiza la felicidad en materia amorosa (Quinault, 1665: 34-37); y el poeta romano Ovidio (Ars amatoria, 2 a.C.-2 d.C.), quien aboga por la indulgencia y comprensión como pilares del amor, con una actitud de pleitesía (obsequium amoris) y esclavitud (servitium amoris) que culmina en la milicia de amor (militia amoris), por la que el enamorado al servicio de la amada se equipara al soldado bajo las órdenes del general (Ovidio Nasón, 2005, 416-417; idem, 2009, 108-109). En definitiva, y con ello concluye la enseñanza del emblema, la mejor lección en el amor es perder algo para que este resulte más dulce, mostrándose el amante diligente y servicial y cumpliendo siempre los deseos de la amada.

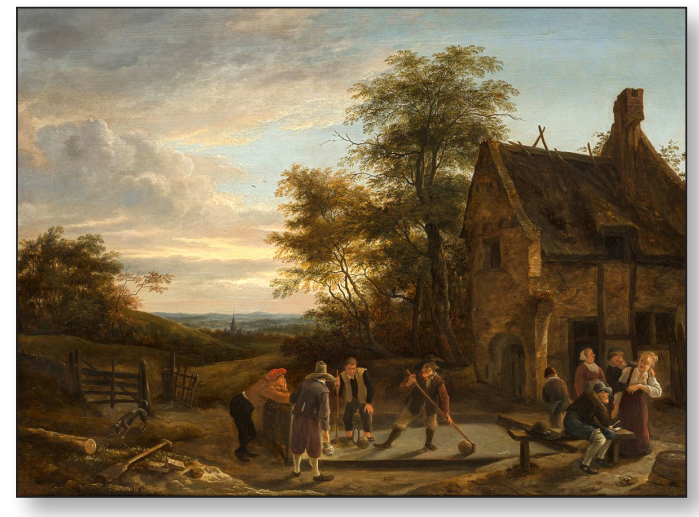

Fig. 10. Jan Steen, Personajes delante de una taberna, divirtiéndose y jugando al beugelen. Koetser Gallery, Zurich.

\section{APLICACIÓN PICTÓRICA DE LA ENSEÑANZA MORAL DEL BEUGELEN}

Conocida la tradición alegórico-emblemática del beugelen, es hora de preguntarnos por su repercusión en la pintura de la Edad Moderna. Partimos del hecho de que su práctica aparece con cierta frecuencia en escenas costumbristas flamenco-holandesas, donde las clases populares disfrutan del juego en medio de un paisaje rural, en cuadros de Pieter Brueghel el Joven, Gillis Mostaert, David Teniers el Joven, Jan Steen [fig. 10] y Adriaen van de Venne, entre otros. La pregunta que surge al respecto es: ¿puede tener en este conjunto algún significado en clave lúdica o amorosa? Sin descartarlo por completo, y más teniendo en cuenta el gusto de estos pintores por la lección moralizante y el hecho de que así ocurre en composiciones similares del juego de bolos (Goodman, 1979: 147-158), creemos que en la mayoría de los casos se trata de dejar constancia de la afición hacia él en las aldeas.

Abandonemos momentáneamente la pintura costumbrista para interesarnos por

pautas de galantería vigentes hasta fines del siglo XVIII, el argumento de Il pastor fido es harto complicado, y tienen cabida igualmente en él otras actitudes amorosas. Guarini, 1999; y López Estrada, 1988: 419-427.

IMAGO, NÚM. 7, 2015, 69-85 


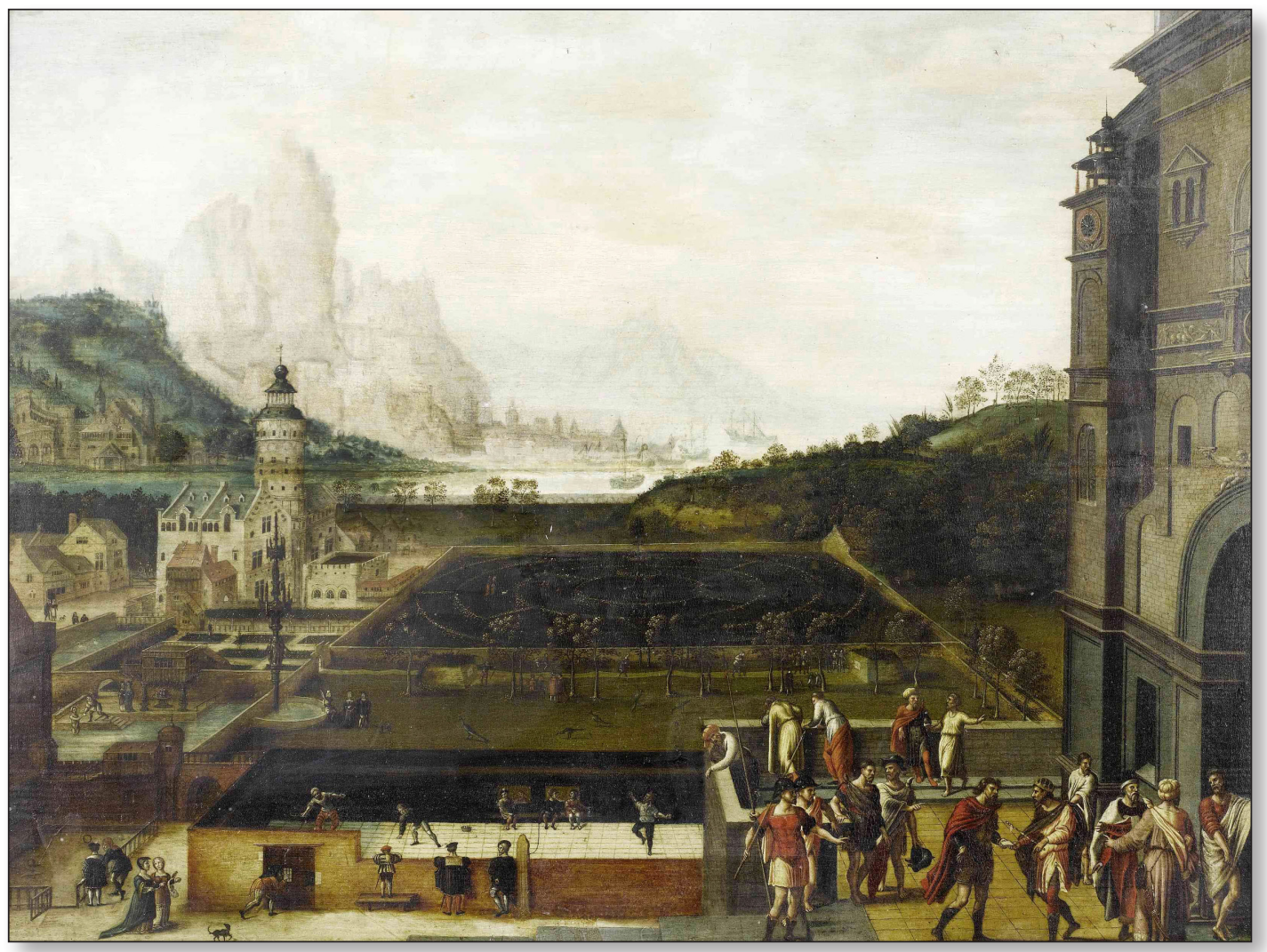

Fig. 11. Lucas Gassel, Historia de David y Betsabé. Colección privada.

la religiosa, en concreto por la historia de David y Betsabé (2 Sam 11), representada en una docena de pinturas flamencas fechadas entre 1530 y 1560, varias de las cuales se atribuyen a Lucas Gassel (1490-1568) [fig. 11]. Obedecen con ligeras variantes al mismo esquema compositivo, en el que el episodio bíblico pasa prácticamente desapercibido ante la fastuosidad del escenario, un palacio renacentista con vistas a un jardín de recreo (Chong, 2003, 137). A la derecha de la composición se levanta el edificio, desde una de cuyas ventanas superiores David observa el baño de Betsabé, a la vez que en la terraza inferior entrega a Urías el documento que le envía a su muerte. A su izquierda quedan los jardines, escenario perfecto para el disfrute de los pasatiempos de la corte, con especial protagonismo para el laberinto, tentador símbolo de los placeres cortesanos de los que resulta difícil escapar. En la distancia cierra la composición un paisaje montañoso con un puerto de mar, en tanto que el primer plano queda reservado a la práctica deportiva: en el centro se disputa un partido de tenis que siguen con atención numerosos espectadores (Gillmeister, 1997: 43-46); y a su izquierda vemos un campo de beugelen en el que, en función de las versiones, hay actividad o simplemente unos curiosos se apoyan en la valla lateral que lo delimita.

La pregunta se nos antoja obligada: la presencia de tenis y beugelen en un lugar destacado, ¿es mero testimonio de las aficiones deportivas de una época, o encierra una intencionalidad más profunda? Para responder a esta cuestión, debemos recordar que 


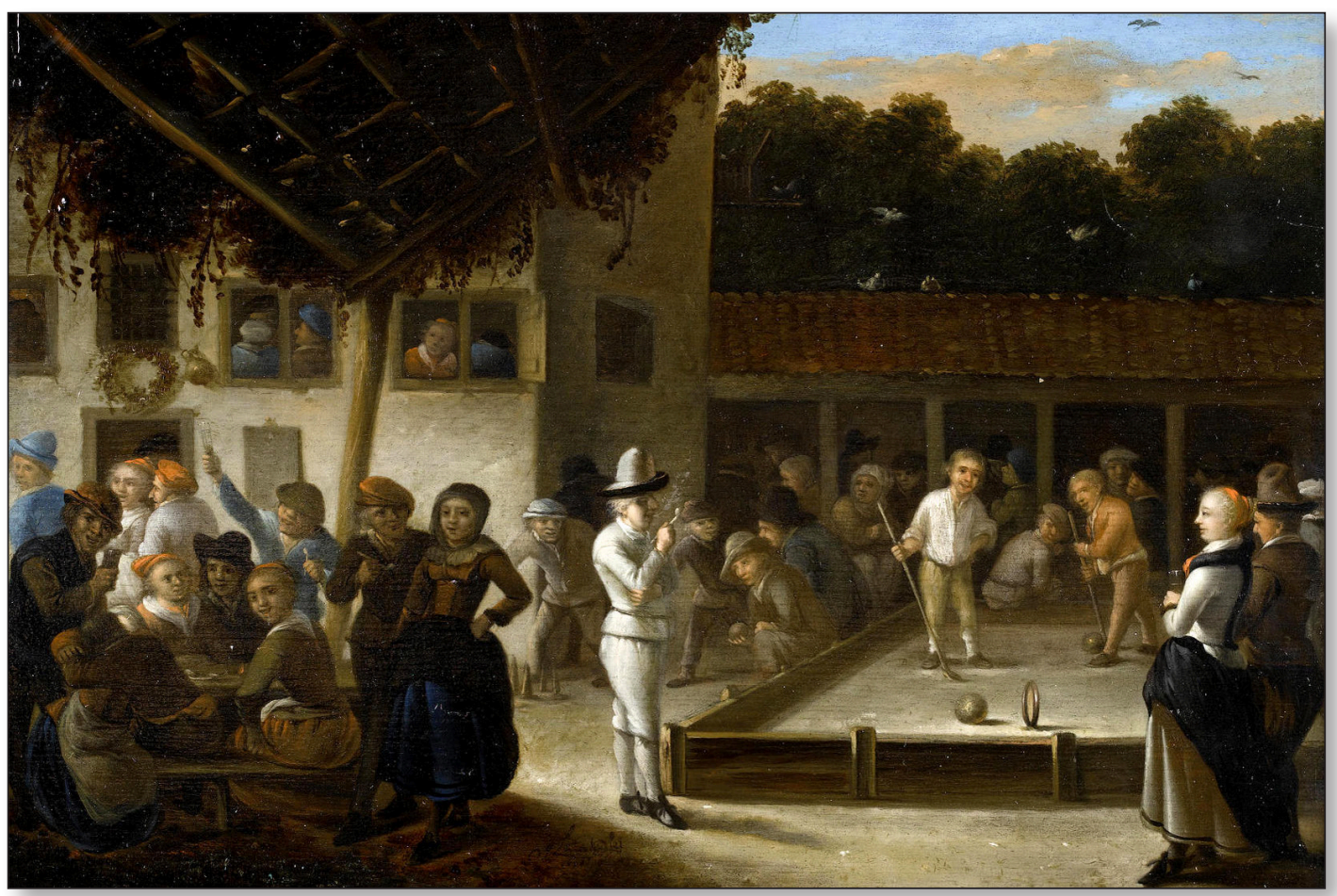

Fig. 12. Gerrit Lundens, Personas jugando a los bolos en el patio de una posada. Casa Bonhams, Londres.

la de David y Betsabé es la historia del amor ilícito con trágico final, convirtiéndose en un ejemplo de las fatales consecuencias que acarrea el amor humano; en consecuencia, es muy probable que el deporte incorpore una lección moral. Nos interesa a este respecto la observación de Cees de Bondt acerca de la principal fuente literaria para estas pinturas, el Menosprecio de corte y alabanza de aldea (1539) de Antonio de Guevara, elogio de la vida campestre y ataque a las intrigas de la corte (Bondt, 2006: 195-197). En varias ocasiones alude a las cualidades corruptoras de los juegos, a los que muchos son arrastrados por "compañeros sospechosos" (recordemos las malas compañías de Veridicus Christianus); y, por si fuera poco, al final del prólogo se refiere al adulterio de David y Betsabé. ${ }^{16}$ Tenemos por tanto un texto literario que conecta el episodio bíblico con los perniciosos efectos del juego, y que sirvió de inspiración a los pintores que interpretaron la escena; a partir de todo ello, consideramos válida la teoría que establece una relación directa entre la presencia de las actividades deportivas y el mensaje que quiere transmitir este conjunto de obras. De hecho, el deporte se encuentra ausente en otros jardines del amor de Gassel ajenos al asunto bíblico en los que sí que aparecen el laberinto y los placeres cortesanos.

Retornemos nuevamente al género costumbrista con Personas jugando a los bolos en el patio de una posada [fig. 12], que firma en 1670 el holandés Gerrit Lundens (16221696). Un grupo de hombres y mujeres bebe, fuma y canta en torno a una mesa, en tanto que en la parte central unos campesinos juegan a los bolos, y a la derecha, en el espacio delimitado al fondo por un 
porche más bajo cubierto con teja, queda una cancha de beugelen con dos hombres en plena partida ante la mirada de un grupo de espectadores, uno de los cuales, de perfil y fumando una pipa, parece actuar como eje de la composición.

Aun con ciertas reservas, consideramos que la pintura encierra un mensaje simbólico en clave amorosa, si bien puede resultar ambiguo. El diferente tratamiento lumínico de la escena no solo pone de manifiesto el dominio de Lundens de la técnica del claroscuro -no en vano el capitán Coq le encargó una copia de la Ronda de noche (1642) de Rembrandt-, sino que puede tener intencionalidad simbólica en una primera diferenciación entre el amor desordenado y el virtuoso, este último representado por la pareja que pasea junto al campo del beugelen. A ello contribuiría el juego en alguna de sus claves emblemáticas que hemos reseñado, y la presencia de varias palomas que, volando desde su cercano palomar, se han posado sobre el tejado y parecen seguir las incidencias de la partida. En el código emblemáticoamoroso, la paloma acostumbra a ser símbolo de fidelidad y fecundidad matrimonial, tal y como lo proponen Junius, Capaccio, Camerarius, Covarrubias y Cats entre otros (García Arranz, 2010: 573-574 y 580).

Sin embargo, hay un elemento que genera incertidumbre en nuestra teoría; y es que la elegante dama, que sostiene una copa de vino, no presta atención al juego ni a su esposo, sino que dirige la mirada al caballero que exhala el humo de su pipa, estableciéndose una tensión visual entre ambos, que parecen resultar ajenos a todo cuanto ocurre a su alrededor. Por tanto, ¿nos encontramos ante un episodio de amor ilícito, para el que servirían igualmente el beugelen, el vino y el tabaco, y las palomas en las proximidades de su palomar, tal y como recogen Heinsius como aviso de los peligros del amor, y Engelgrave para advertir que la reincidencia en determinados actos pecaminosos puede convertirse en un acto difícil de erradicar? (García Arranz, 2010: 575-576 y 603). En tal caso, el significado de la pintura se situaría en el extremo opuesto del anterior. Sea como fuere, comprobamos una vez más la capacidad de los pintores de los Países Bajos para introducir en sus cuadros mensajes cifrados con una fina ironía y sentido del humor.

Concluimos con Fiesta en el jardín (1677) [fig. 13], en ocasiones denominada El hijo pródigo, si bien no parecen existir suficientes elementos para identificarla con la parábola evangélica (Kirschenbaum, 1977: 52-55, 151 y 227). Se trata de una de las últimas obras del pintor holandés Jan Steen (16261679) que define su estilo tardío, a base de una pincelada nerviosa y una paleta luminosa y refinada a la que se suma la alegría natural del jardín del amor que, a la vez que revive las fiestas al aire libre de comienzos del siglo XVII, anticipa el galanteo rococó francés (Rosenberg, Slive y Kuile, 1994: 241-242). Mas el refinamiento de Steen no se limita únicamente a cuestiones técnicas, sino que se extiende a las simbólicas; es más, Chapman (1996: 257-259) considera que el pintor eleva la complejidad de la obra al crear dos realidades distintas pero a la vez paralelas: la de los personajes en primer plano, de trajes y gestos teatrales que conforman la imaginaria puesta en escena de un alegórico jardín del amor, y la de los hombres y mujeres dispuestos al otro lado de la balaustrada que pertenecen al mundo real. De hecho, la pintura manifiesta cierto sentido escenográfico, como si los personajes del fondo asistieran a una representación teatral.

Para desentrañar su significado, debemos tener presente que el cuadro fue encargado, quizás con motivo de un enlace matrimonial, por la familia Paedts, que gobernaba en la ciudad de Leyden en 1677, cuyo escudo de armas figura en el cojín que reposa sobre el banco del ángulo inferior izquierdo, y cuya mansión se asemejaba a la que se levanta al fondo del jardín. A juicio de Chapman, la pintura parece haber sido concebi- 


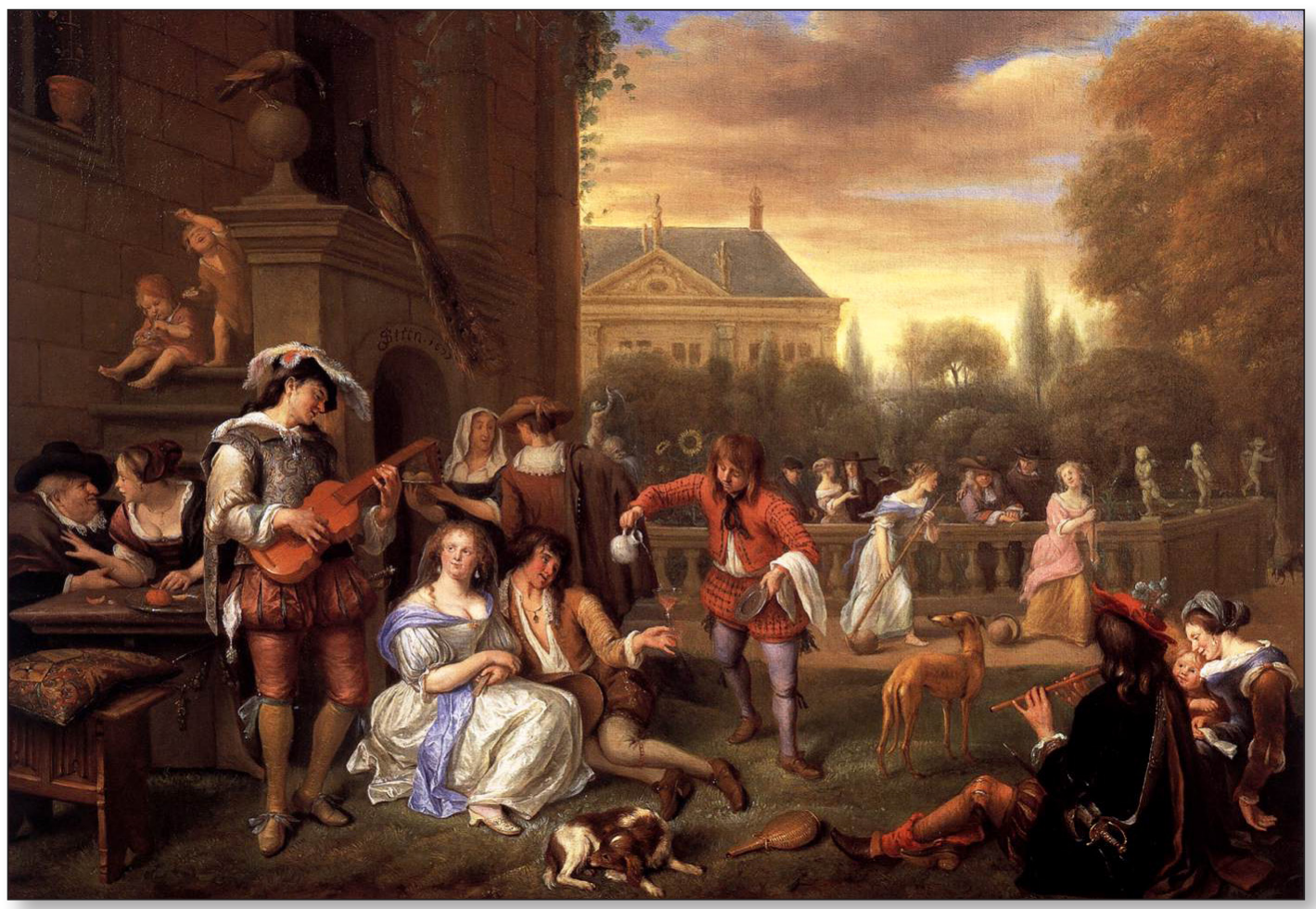

Fig. 13. Jan Steen, Fiesta en el jardín. Colección privada, Bélgica.

da para agradar a un cliente noble, dado el gusto de esta clase social por los jardines del amor que reinterpretaban un tema de origen medieval. Compartiendo tal opinión, sugerimos una lectura de la obra de izquierda a derecha, avanzando en los grados de perfeccionamiento del amor; recordemos a este respecto que el carácter narrativo en el comportamiento de varias parejas no es nuevo en la pintura de Steen, quien echa mano de este recurso en obras como La pareja de baile (1663) (Wheelock, 1996: 163-165).

Nuestra lectura da comienzo en el coqueteo entre el hombre viejo y la mujer joven a la izquierda de la mesa, que sugiere en amor licencioso y mal emparejado; a continuación, la pareja del centro muestra aparentemente actitud amorosa, pero Steen rectifica esta visión inicial haciendo girar las cabezas de los supuestos amantes en dirección opuesta, buscando él los placeres del vino y ella los del amor ilícito en el elegante guitarrista; finalmente, la pareja de la derecha, evocadora de la pintura pastoril veneciana, asume los valores del matrimonio y del amor verdadero, reflejado en la descendencia de los hijos.

Esta lectura secuencial encuentra su apoyo en un conjunto de detalles con un alto grado de codificación que incide en los valores del matrimonio y que ya han hecho acto de presencia en obras anteriores del pintor, quien introduce no obstante como principio de su reflexión el recordatorio de la fugacidad de la vida, el clásico homo bulla personificado en los niños soplando burbujas en la escalinata del edificio lateral. ${ }^{17}$

17. Los niños soplando burbujas como referencia visual al homo bulla aparecen también en otras pinturas de Steen como La pareja de baile (1663) y La vida del hombre (1665). Sobre este tema, véase Stechow, 1938: 223-238; Bialostocki, 1973: 185-226; y Emmer, 1987: 327-334.

IMAGO, NÚM. 7, 2015, 69-85 
A partir de aquí, se suceden las referencias: la naranja hacia la que apunta la mujer de la izquierda es símbolo de la fertilidad, convertida en este caso en metáfora de la infértil unión entre amantes desiguales; ${ }^{18}$ el par de pavos reales macho y hembra alude al cortejo amoroso, aunque por su ubicación junto a los niños también puede incidir en el mensaje de vanitas, recogido en algunos repertorios emblemáticos (van der Veens, 1642, 92-97); el girasol simboliza la fidelidad, dado su hábito de orientarse siempre hacia el sol (Peacock, 2006: 135-175), virtud reforzada por los perros; y también encierra un significado alegórico en relación con el amor el trío de cupidos que decora la balaustrada justo debajo de la madre con su hijo (la ubicación no parece casual), versión escultórica de los putti celestiales de Rubens en El jardín del Amor (h. 1633-34), cuyas actitudes -patinando, orinando y avanzando a ciegas- encuentran su correspondencia en los repertorios emblemáticos de la época. ${ }^{19}$ Recordemos a este propósito que Steen recurre con cierta frecuencia a la estrategia de «la escultura dentro de la pintura» para moralizar acerca de los contenidos de sus cuadros (Scholten, 2004-2005, 54-89).

A todo ello se sumaría el juego del beugelen, que el pintor ya había representado en anteriores ocasiones, vinculado a la temática popular de campesinos en sus aldeas; pero si comparamos aquellas imágenes con esta, comprobamos de inmediato que aquí resulta irreal: la ausencia de un terreno de juego definido y, sobre todo, el hecho de ser practicado por dos damas que recuerdan a las emblemáticas figuras femeninas de Ludovicus van Leuven, constituyen un hecho excepcional que dota a la escena de carácter alegórico, nos inclinamos a pensar que como guía del amor virtuoso regido por los principios de la religión. ${ }^{20}$

\section{CONCLUSIÓN}

El anterior recorrido simbólico-emblemático por el beugelen pone de manifiesto su riqueza conceptual que trasciende de la mera práctica deportiva para asumir valores y significados más complejos, casi siempre en relación con el amor y sus consecuencias, ya sean estas positivas o negativas. Emblemática, arte y deporte se dan cita una vez más para mostrar toda su capacidad a la hora de transmitir una lección moral e ir más allá de lo meramente visual. ${ }^{21}$

\section{BIBLIOGRAFÍA}

Adams, A., Rawles, S. y Saunders, A. [1999]. A Bibliography of French Emblem Books of the Sixteenth and Seventeenth Centuries, vol. I. Gèneve, Librarie Droz.

AtienZA, J. G. [1995]. Los saberes alquímicos. Diccionario de pensadores, símbolos y principios, Madrid, Temas de Hoy.

18. Sobre el simbolismo de la naranja, véase Bedaux, 1990: 48.

19. Aun sin poder extendernos en el tema, un rápido recorrido nos lleva a libros como: Amorum emblemata (Otto Vaenius, 1608); Ambacht van Cupido (Daniel Heinsius, 1613 y 1616); Thronus Cupidinis (anónimo, 1620); Emblemata amatoria (anónimo, 1690); y Devises et emblemes (Daniel de la Feuille, 1691), para el caso de los cupidos patinando y avanzando a ciegas. Y, para Cupido orinando, a obras como Venus y Cupido (h. 1525) de Lorenzo Lotto, La Bacanal de los Andrios (1523-1526) de Tiziano, y Flora con putti (siglo XVII) de Francesco Albani. Sobre esta última actitud, véase González de Zárate, 2013: 47-69; y Rodríguez Moya y Mínguez Cornelles, 2013: 21 y 221-222.

20. Chapman por el contrario lo considera metáfora del amor furtivo o frívolo, basándose en el dicho: «En el juego del amor, el que pierde siempre gana", que ya hemos visto aparecer en los libros de emblemas.

21. Nuestro agradecimiento a Carme López Calderón, Silvia Cazalla y Mercedes Mutiloa por su inestimable ayuda en la traducción de los textos en diferentes idiomas de los libros de emblemas aquí citados. 
AzAnZa LÓPEZ, J. J. [2011-2012]. "Tradición alegórico-emblemática de la raqueta del jeu de paume como objeto de vanitas", Boletín de Arte de la Universidad de Málaga, 32-33, 11-39.

AzAnza LóPez, J.J. [2015]. «Emblemática en el sferisterio: tradición alegórico-emblemática del pallone col bracciale», en J. M. Morales Folguera, F. J. Talavera Esteso y R. Escalera Pérez (eds.), Anejos de Imago, 3. Confluencia de la imagen y la palabra. Emblemática y artificio retórico, Málaga, Universidad de Málaga y Sociedad Española de Emblemática, 103-117.

Bedaux, J. B. [1990]. The Reality of Symbols: Studies in the Iconology of Netherlandish Art 1400-1800, The Hague, Maarssen.

Bergström, I. [1956]. Dutch Still-Life Painting in the Seventeenth Century, London and New York, Thomas Yoseloff.

Bialostocki, J. [1973]. "Arte y vanitas», en Estilo e Iconografía. Contribución a una ciencia de las artes, Barcelona, Barral Editores, 185-226.

Biblia latina, cum postillis Hugonis de Sancto Charo [h. 1500]. Tertia pars, Basilea, Johann Amerbach et Anton Koberger.

Boecio [1997]. La consolación de la filosofía (ed. L. Pérez Gómez), Madrid, Akal.

Bond, C. de [2006]. Royal Tennis in Renaissance Italy, Turnhout, Brepols Publishers.

Chapman, H. P. [1996]. "Garden Party», en Jan Steen. Painter and Storyteller, Washington y Ámsterdam, Nacional Gallery of Art y Rijksmuseum, 257-259.

Chong, A. [2003]. "Landscape with David and Bathsheba», en Eye of the Beholder, Boston, ISGM and Beacon Press, 137.

Comenius, J. A. [1657]. Orbis Sensualium Pictus, London, Printed for S. Leacroft (ed. 1777).
Daly, P. M. [1999]. «Emblematic Publications by the Jesuits of the Flanders Belgium Province to the Year 1700», en J. Manning y M. van VAeck (eds.), The Jesuits and the emblem tradition. Selected papers of the Leuven international emblem conference, 18-23 August, 1996, Imago Figurata. Studies, vol. la, Turnhout, Brepols, 249278.

DAvID, J. [1601]. Veridicus Christianus, Antverpiae, ex Officina Plantiniana.

De la PezA, E. [1961]. «El significado de cor en san Agustín", Revue des Études Agustiniennes, 7, 339-368.

Emblems and Alchemy (eds. A. Adams y S. J. Linden) [1998]. Glasgow, Glasgow Emblem Studies.

Emmer, M. [1987]. "Soap Bubbles in Art and Science: From the Past to the Future of Math Art», Leonardo, 20, 4, 327-334.

Erasmo [1522]. Colloquia Familiaria, Amsterodami, Apud Guili Lansbonium (ed. 1621).

Fulcanelli [2009]. El Misterio de las Catedrales, Murcia, Nemira.

García Arranz, J. J. [2010]. Symbola et emblemata avium. Las aves en los libros de emblemas y empresas de los siglos XVI y XVII, A Coruña, SIELAE.

German Engravings, Etchings and woodcuts, ca. 1400-1700 [1954]. Vol. I, Amsterdam, Menno Hertzberger.

Gillmeister, H. [1997]. Tennis: A Cultural History, London, Leicester University Press.

GonzÁlez de ZÁrate, J. M. [2013]. «Laurentius Lotus [Lorenzo Lotto]. De amore», Imago. Revista de Emblemática y Cultura Visual, 5, 47-69.

Goodman, E. [1979]. «The Sources of Pieter de Hooch's The Game of Skittles», Studies in Iconography, 5, 1979, 147-158.

Guarini, G. B. [1976]. Il pastor fido (ed. L. FAssò), Torino, Einaudi.

Guarini, G. B. [1999]. Il Pastor Fido (ed. E. Selmi), Venezia, Marsilio Editori. 
Heuer, Ch. P. [2009]. The City Rehearsed. Object, architecture, and print in the worlds of Hans Vredeman de Vries, New York, Routledge.

Hollstein's Dutch o Flemish Etchings, Engravings and Woodcuts, 1450-1700 [1995]. T. XLIV. Maarten de Vos. Plates, Part II, Rotterdam, Sound \& Vision Interactive.

Insolera, M. y SALviucci, L. [1996]. La spiritualité en images aux Pays-Bas méridionaux dans les livres imprimés des XVI et XVII siècles. Leuven, Éditions Peeters.

Kemp, M. [2000]. La ciencia del arte. La óptica en el arte occidental de Brunelleschi a Seurat, Madrid, Akal.

Kirschenbaum, B. D. [1977]. The Religious and Historical Paintings of Jan Steen, Oxford, Phaidon.

Le centre de l'amour decouvert soubs divers emblesmes galans et facetieux [1680]. A Paris, Chez Cupidon (ed. 1687).

López Estrada, F. [1988]. «La recreación española de Il Pastor Fido de Guarini por los tres ingenios españoles Solís, Coello y Calderón de la Barca», en Varia Bibliographica. Homenaje a José Simón Díaz, Kassel, Reichenberger, 419-427.

López PozA, S. [2007]. "Alonso de Ledesma and the Spanish epigrams in the polyglot edition of Vaenius's Amoris divini emblemata», en E. Stronks y P. Boot (eds.), Learned Love. Proceedings of the Emblem Project Utrecht Conference on Ducht Love Emblems and the Internet (November 2006), The Hague, DANS Symposium Publications 1, 93-109.

Macarde, P. [2007]. Hermannus Schottennius Hessus. Confabulationes tironum litterariorum (Cologne, 1525) (ed. P. Macardle), Durham, Durham University.

Menosprecio de corte, y alabanza de aldea [1735]. Copilado por el Illmo. Y Rmo. Señor Don Antonio de Guevara... Quinta Impresión. En Madrid, Por Juan Valentino.
Morgan, R. [1995]. Tennis. The Development of the European Ball Game, Oxford, Ronaldson.

Moseley, Ch. [1989]. A Century of Emblems. An Introductory Anthologhy. Aldershot, Scholar Press.

Orenstein, N. M. [2001]. Pieter Brueghel the Elder: Drawings and Prints, New York, The Metropolitan Museum of Art.

Ovidio Nasón, P. [2005]. Obras completas. Arte de Amar (introducción, edición y notas críticas de A. Ramírez De Verger), Madrid, Espasa.

Ovidio Nasón, P. [2009]. Arte de amar (traducción, notas e introducción de A. ScHniebs y G. Daujotas), Buenos Aires, Colihue.

PeAcock, J. [2006]. The Look of Van Dyck. The Self-Portrait with a Sunflower and the Vision of the Painter, Aldershot, Ashgate.

Porteman, K. [2000]. "The Use of the Visual in Classical Jesuit Teaching and Education", Paedagogica Historica, 36, 1, 179196.

Praz, M. [1989]. Imágenes del Barroco (estudios de emblemática), Madrid, Siruela.

Quinault, Ph. [1665]. Astrate, Roy de Tyr. Tragedie. A Paris, Chez Guillaume de Luyne.

Rodríguez Moya, I. y Mínguez Cornelles, V. [2013]. Himeneo en la corte. Poder, representación y ceremonia nupcial en el arte y la cultura simbólica, Madrid, CSIC.

Rosenberg, J., Slive, S. y Kuile, E. H. ter [1994]. Arte y arquitectura en Holanda: 1600-1800, Madrid, Cátedra.

Scholten, F. [2004-2005]. "The Larson Family os Statuary Founders: SeventeenthCentury Reproductive Sculpture for Gardens and Painter's Studios», Simiolus: Netherlands Quarterly for the History of Art, 31, 1/2, 54-89.

Schotten, H. [1525]. Confabulationes tyronum literariorum, Cologne.

Stechow, W. [1938]. "Homo bulla», The Art Bulletin, 20/2, 1938, 223-238. 
Sullivan, M. A. [1994]. Brueghel's peasants. Art and Audience in the Northern Renaissance, Cambridge, Cambridge University Press.

The Illustrated Bartsch [1980]. No 16, vol. 8. Early German Masters, New York, Abaris Books.

The New Hollstein Dutch o Flemish Etchings, Engravings and Woodcuts, 1450-1700 [2005]. T. 38. The Collaert Dinasty. Part VI, Ouderkerk aan den Ijssel, Sound \& Vision Publishers.

The New Hollstein Dutch $\theta$ Flemish Etchings, Engravings and Woodcuts, 1450-1700 [2006]. T. 48. Pieter Brueghel The Elder. Ouderkerk aan den Ijssel, Sound \& Vision Publishers.
VAn Der Veens, I. [1642]. Zinne-Beelden, oft Adams Appel, Amsterdan, By Everhard Cloppenburgh.

Van Leuven, L. [1629]. Amoris divini et humani antipathia. Antvuerpiae, apud Michaëlem Snyders.

VRedeman de VRIes, J. [1583]. Hortorum Viridariorumque elegantes $\theta$ multiplicis formae, Antuerpiae, Philippus Gallaeus.

WARLICK, M. E. [2003]. Las piedras de la alquimia, Madrid, Adaf.

Wheelock, A. K. [1996]. "The Dancing Couple», en Jan Steen. Painter and Storyteller, Washington y Ámsterdam, Nacional Gallery of Art y Rijksmuseum, 163-165. 
